1. A. Martin, Bull. Philos. Soc. Wash., v. 10, 1887, p. 107, in Smithsonian Coll., 33, 1888.

2. S. SASTRY, J. London Math. Soc., v. 9, 1934, p. 242.

3. L. E. Dickson, History of the Theory of Numbers, Carnegie Institute of Washington, Vol. 2, 1923, p. 682 .

\title{
Statistics on Certain Large Primes
}

\section{By M. F. Jones, M. Lal and W. J. Blundon}

Introduction. In any heuristic approach to the distribution of prime numbers, lists of primes are necessary and it is to this end that many such lists have been prepared. For primes up to $37 \cdot 10^{6}$, Lehmer [1] has made detailed comparisons with some of the conjectures of Hardy and Littlewood [2] and, more recently, primes up to 104395289 have been listed [3] and statistics compiled [4].

The purpose of this investigation has been to determine whether the conjectures concerning the number of primes, twins, triples and quadruples in a given interval $x$ to $x+\Delta x$ continue to hold for somewhat larger $x$ than have previously been considered.

The following ranges were chosen:

$$
10^{n} \rightarrow 10^{n}+150,000,
$$$$
n=8(1) 15,
$$

and the primes were found using the following algorithm.

Let us define a sequence $\left\{S_{k}\right\}$ of $k$ odd numbers where

$$
S_{k}=x+2(k-1) \leqq{p_{n}}^{2}
$$

with $p_{i}=2 i+1, i=1,2, \cdots n$ and $x>p_{n}$, and a further sequence $\left\{r_{i}\right\}$ such that

$$
x \equiv r_{i}\left(\bmod p_{i}\right) .
$$

Then all composite numbers in the sequence $\left\{S_{k}\right\}$ fall in the sequence $\left\{C_{i m}\right\}$ where

$$
C_{i m}=x+\left(a_{i} \cdot p_{i}-r_{i}\right)+2 m p_{i}, \quad m=0,1, \cdots
$$

with

$$
\begin{aligned}
& \begin{array}{lll}
a_{i}=0 & \text { for } r_{i} & \text { zero }
\end{array} \\
& =1 \quad \text { even, } \\
& =2 \quad \text { odd }
\end{aligned}
$$

The above algorithm was coded for an IBM 1620 with $40 \mathrm{~K}$ core storage, and by representing two odd numbers by one core address, ${ }^{*}$ we are able to determine all primes in a block of 150,000 numbers in a single run. The $r_{i}$ 's are found by direct division if $p_{i} \leqq\left(2 p_{n}{ }^{11 / 3}+1\right)$ and by Alway's method [5] if otherwise. The time required for such a run is very little larger than that required to establish one prime in the same range.

Received February 21, 1966. Revised June 22, 1966.

* Each available core location represents two odd numbers, differing by 75,000 and is initially set to a flagged record mark. If in the sieve, the lower number is found to be composite, the record mark is cleared, and if the higher number is so found, the flag is cleared. 
TABLE 1

The Riemann and Chebyshev Counts

\begin{tabular}{l|r|r}
\hline$x$ & \multicolumn{1}{|c|}{ Riemann Count } & \multicolumn{1}{|c}{ Chebyshev Count } \\
\cline { 1 - 2 } $10^{8}$ & 5761551.9 & 5762208.3 \\
$10^{9}$ & 50847455.4 & 50849233.9 \\
$10^{10}$ & 455050683.3 & 455055613.5 \\
$10^{11}$ & 4118052494.6 & 4118066399.6 \\
$10^{12}$ & 37607910542.2 & 37607950279.8 \\
$10^{13}$ & 346065531065.8 & 346065645809.0 \\
$10^{14}$ & 3204941731601.7 & 3204942065690.9 \\
$10^{15}$ & 29844570495886.9 & 29844571475286.5 \\
\hline
\end{tabular}

Results. All primes in the ranges

$$
10^{n} \rightarrow 10^{n}+150,000, \quad n=8(1) 15
$$

have been tabulated and it is intended to distribute a limited number of copies to interested mathematicians. A brief summary of the results is presented as follows:

(a) Number of primes: Riemann's formula

(1) $P(x)=\operatorname{Li}(x)-\operatorname{Li}(\sqrt{ } x) / 2-\operatorname{Li}(\sqrt[3]{x}) / 3-\operatorname{Li}(\sqrt[5]{x}) / 5+\operatorname{Li}(\sqrt[6]{x}) / 6 \cdots$

for the number of primes less than $x$ is outstanding for its accuracy. Lehmer [6] shows that $P(x)$ is given by

$$
P(x)=1+\ln x / S_{2}+\ln ^{2} x /\left(2.2 ! S_{3}\right)+\ln ^{3} x /\left(3.3 ! S_{4}\right)+\cdots
$$

where

$$
S_{n}=1+\frac{1}{2}^{n}+\frac{1}{3}^{n}+\frac{1}{4}^{n}+\cdots
$$

and the above expression was used to evaluate the Riemann count (for $P\left(10^{15}\right)$, 100 terms were used); Table 1 gives the values of

$$
P\left(10^{n}\right) \text { for } n=8(1) 15
$$

and also tabulates the Chebyshev count

$$
\int_{2}^{x} d x / \ln x,
$$

all values being rounded to one decimal.

In Table 2, we compare the actual prime counts with those predicted by the Riemann and Chebyshev formulae. The agreement between the latter two is due to the difference $P(x)-L i(x)$ as defined by (1) being insignificant as compared to $P(x)$.

(b) Twins, triples and quadruples: If we let $P_{2}(p, p+d)$ be the number of twin primes differing by $d$ such that $x \leqq p, p+d \leqq y$, then Hardy and Littlewood have conjectured that

$$
\begin{gathered}
P_{2}(p, p+2) \sim 2 C_{2} \int_{x}^{y} d x / \ln ^{2} x \\
P_{2}(p, p+4) \sim P_{2}(p, p+2)
\end{gathered}
$$


TABLE 2

Numbers of Primes and Maximum Differences

\begin{tabular}{|c|c|c|c|c|c|}
\hline Range $x \rightarrow x+\Delta$ & $\begin{array}{l}\text { Actual } \\
\text { Count }\end{array}$ & $\begin{array}{c}P(x+\Delta) \\
\quad-P(x)\end{array}$ & $\int_{x}^{x+\Delta} d y / \ln y$ & $\left|\begin{array}{c}\operatorname{Maxi}- \\
\operatorname{mum} \Delta_{i}\end{array}\right|$ & Prime $p_{i+1}$ \\
\hline $10^{8} \rightarrow 10^{8}+\Delta$ & 8154 & 8142.3 & 8142.7 & 168 & $58851+10^{8}$ \\
\hline $10^{9} \rightarrow 10^{9}+\Delta$ & 7242 & 7238.1 & 7238.2 & 176 & $97797+10^{9}$ \\
\hline $10^{10} \rightarrow 10^{10}+\Delta$ & 6511 & 6514.4 & 6514.4 & 182 & $5139+10^{10}$ \\
\hline $10^{11} \rightarrow 10^{11}+\Delta$ & 5974 & 5922.2 & 5922.4 & 148 & $\left\{\begin{array}{r}97819+10^{11} \\
107611+10^{11}\end{array}\right\}$ \\
\hline $10^{12} \rightarrow 10^{12}+\Delta$ & 54 & 5428.7 & 542 & 22 & $11641+10^{12}$ \\
\hline $10^{13} \rightarrow 10^{13}+\bar{\Delta}$ & 5065 & 5011.1 & 5011.1 & 234 & $129723+10^{13}$ \\
\hline $10^{14} \rightarrow 10^{14}+\Delta$ & 4643 & 4653.2 & 4653.2 & 300 & $13839+10^{14}$ \\
\hline $10^{15} \rightarrow 10^{15}+\Delta$ & 4251 & 4342.9 & 4342.9 & 276 & $24549+10^{15}$ \\
\hline
\end{tabular}

and

$$
P_{2}(p, p+6) \sim 2 P_{2}(p, p+2)
$$

where

and

$$
C_{n}=\prod_{p>n} p^{n-1}(p-n) /(p-1)^{n}
$$

$C_{2}=0.6601618158 \cdots, \quad C_{3}=0.6531663546 \cdots, \quad C_{4}=0.3074948788 \cdots$.

Similarly, with obvious notation, they have conjectured that for triples

$$
P_{3}(p, p+2, p+6) \sim C_{3} \int_{x}^{y} d x / \ln ^{3} x
$$

and

$$
P_{3}(p, p+4, p+6) \sim P_{3}(p, p+2, p+6),
$$

and for quadruples

$$
P_{4}(p, p+2, p+6, p+8) \sim \frac{27}{2} C_{4} \int_{x}^{y} d x / \ln ^{4} x
$$

and

$$
P_{4}(p, p+4, p+6, p+10) \sim 2 P_{4}(p, p+2, p+6, p+8) .
$$

Table 3 shows the general validity of these conjectures although several anomalies are present. Noteworthy among these, are the deficiency of twin primes in the range $10^{11} \rightarrow 10^{11}+\Delta$, and the ratio of the two triples in the range $10^{14} \rightarrow$ $10^{14}+\Delta$.

(c) Arithmetic progressions: In Table 4 we give a breakdown of the numbers of arithmetic progressions between successive primes. The progressions with 3 and 4 terms have common differences which are multiples of 6 , whilst the single progression with 5 terms has a common difference of 30 . The first term of this latter progression is

$$
10^{10}+24493
$$


TABLE 3

Numbers of Twins, Triples and Quadruples

Columns A give actual counts

Columns $\mathbf{C}$ give conjectured counts

$\Delta=150,000$

\begin{tabular}{|c|c|c|c|c|c|c|c|c|c|c|c|c|c|}
\hline \multirow{3}{*}{ Range } & \multicolumn{5}{|c|}{ Twins } & \multicolumn{4}{|c|}{ Triples } & \multicolumn{4}{|c|}{ Quadruples } \\
\hline & \multicolumn{2}{|c|}{$\begin{array}{c}P_{2}(p \\
p+2)\end{array}$} & $\begin{array}{r}P_{2}(p \\
p+4)\end{array}$ & \multicolumn{2}{|c|}{$P_{2}(p, p+6)$} & \multicolumn{2}{|c|}{$\begin{array}{c}P_{3}(p \\
p+2 \\
p+6)\end{array}$} & \multicolumn{2}{|c|}{$\begin{array}{c}P_{3}(p \\
p+4 \\
p+6)\end{array}$} & \multicolumn{2}{|c|}{$\begin{array}{c}P_{4}(p, p+ \\
4, p+6 \\
p+8)\end{array}$} & \multicolumn{2}{|c|}{$\begin{array}{c}P_{4}(p, p+ \\
2, p+6 \\
p+10)\end{array}$} \\
\hline & A & $\mathrm{C}$ & $\mathbf{A}$ & A & C & A & & $\mathrm{C}$ & $\mathbf{A}$ & A & $\mathrm{C}$ & $\mathbf{A}$ & $\mathrm{C}$ \\
\hline $10^{8} \rightarrow 10$ & 601 & 583. & 588 & 1141 & 1067.2 & 70 & 68 & 3.6 & 69 & 4 & 5.4 & 10 & 10.8 \\
\hline $10^{9} \rightarrow 10^{9}+\Delta$ & 466 & 461 . & 485 & 931 & 932.3 & 53 & 48 & & 55 & 3 & 3.4 & 7 & 6.8 \\
\hline $10^{10} \rightarrow 10^{10}+\Delta$ & 389 & 373 . & 395 & 732 & 747 & 40 & 35 & & 39 & 3 & 2.2 & 6 & 4.4 \\
\hline $10^{11} \rightarrow 10^{11}+\Delta$ & 276 & 308 . & 285 & 634 & 617.4 & 29 & 26 & .4 & 28 & 1 & 1.5 & 2 & 3.0 \\
\hline $10^{12} \rightarrow 10^{12}+\bar{\Delta}$ & 276 & 259 . & 260 & 494 & 518 & 22 & 20 & & 19 & 1 & 1.1 & 1 & 2.1 \\
\hline $10^{13} \rightarrow 10^{13}+\Delta$ & 208 & 221 . & 229 & 462 & 442 & 14 & 16 & .0 & 16 & 2 & 0.8 & 2 & 1.6 \\
\hline $10^{14} \rightarrow 10^{14}+\Delta$ & 186 & 190. & 189 & 368 & 391.2 & 12 & 12 & .8 & 5 & 0 & 0.6 & 0 & 1.2 \\
\hline $10^{15} \rightarrow 10^{15}+\Delta$ & 161 & 166. & 146 & 290 & 332.0 & 8 & 10 & & 8 & 1 & 0.4 & 2 & 0.9 \\
\hline
\end{tabular}

TABLE 4

Numbers of Arithmetic Progressions

$m$ is the number of primes in the progression

$d$ is its common difference

$\Delta=150,000$

\begin{tabular}{|c|c|c|c|c|c|c|c|c|c|c|c|c|c|c|}
\hline \multirow{2}{*}{ Range } & \multirow{2}{*}{$m$} & \multicolumn{13}{|c|}{$d$} \\
\hline & & 6 & 12 & 18 & 24 & 30 & 36 & 42 & 48 & 54 & 60 & 66 & 72 & Totals \\
\hline $10^{8} \rightarrow 10^{8}+\Delta$ & 3 & 93 & 65 & 27 & 17 & 13 & 1 & 4 & 1 & 1 & 一 & - & - & 222 \\
\hline & 4 & 3 & 6 & 3 & - & 1 & - & - & 一 & - & - & - & - & 13 \\
\hline $10^{9} \rightarrow 10^{9}+\Delta$ & 3 & 94 & 55 & 29 & 11 & $1 \overline{1}$ & 3 & 1 & 一 & - & 1 & 一 & - & 205 \\
\hline $10^{10} \rightarrow 10^{10}+\Delta$ & $\begin{array}{l}4 \\
3\end{array}$ & $\begin{array}{l}10 \\
54\end{array}$ & $\begin{array}{r}5 \\
38\end{array}$ & $\begin{array}{r}1 \\
21\end{array}$ & $\overline{12}$ & $\overline{14}$ & 5 & $\overline{2}$ & 二 & - & $\overline{2}$ & 二 & - & $\begin{array}{r}16 \\
148\end{array}$ \\
\hline $10^{10} \rightarrow 10^{10}+\Delta$ & $\begin{array}{l}3 \\
4\end{array}$ & $\begin{array}{r}54 \\
3\end{array}$ & $\begin{array}{r}30 \\
1\end{array}$ & 21 & 12 & $\begin{array}{r}14 \\
3\end{array}$ & $\stackrel{5}{-}$ & $\underline{2}$ & - & 二 & $\underline{2}$ & 二 & 二 & $\begin{array}{r}148 \\
7\end{array}$ \\
\hline $10^{11} \rightarrow 10^{11}+\Delta$ & 3 & 39 & 31 & 21 & 16 & 15 & 1 & - & 2 & 1 & 2 & 2 & - & 130 \\
\hline & 4 & $\begin{array}{r}2 \\
33\end{array}$ & $\overline{10}$ & 3 & 1 & $1 \frac{1}{17}$ & - & $\overline{1}$ & - & - & $\overline{3}$ & - & - & $\begin{array}{r}7 \\
105\end{array}$ \\
\hline $10^{12} \rightarrow 10^{12}+\Delta$ & $\begin{array}{l}3 \\
4\end{array}$ & $\begin{array}{r}33 \\
1\end{array}$ & $\begin{array}{r}18 \\
1\end{array}$ & $\begin{array}{r}19 \\
2\end{array}$ & - & 17 & 4 & 1 & 3 & 二 & $\underline{3}$ & - & - & $\begin{array}{r}105 \\
4\end{array}$ \\
\hline $10^{13} \rightarrow 10^{13}+\Delta$ & 3 & 28 & 26 & 14 & 8 & 10 & 4 & 6 & 1 & 2 & 1 & - & - & 100 \\
\hline & 4 & & 2 & & - & & - & & & & - & - & - & 3 \\
\hline $10^{14} \rightarrow 10^{14}+\Delta$ & 3 & 32 & 18 & 9 & 8 & 8 & 2 & 4 & 2 & 1 & - & - & 1 & 85 \\
\hline$+\mathbf{A}$ & $\begin{array}{l}4 \\
3\end{array}$ & $\begin{array}{r}4 \\
13\end{array}$ & $\overline{11}$ & $\overline{8}$ & 5 & 2 & $\overline{8}$ & 2 & $\overline{9}$ & $\overline{1}$ & $\overline{1}$ & 二 & 二 & 6 \\
\hline $10^{*} \rightarrow 10^{\circ}+\Delta$ & 4 & 10 & - & - & $\underline{-}$ & $\begin{array}{l}0 \\
1\end{array}$ & - & - & - & $\perp$ & $\perp$ & - & - & 1 \\
\hline
\end{tabular}

In addition there is a 5 -term progression, with common difference 30 , whose first term is $10^{10}+24493$.

The maximum common difference in any of the ranges is 72 ; this occurs in a 3 -term progression whose first term is

$$
10^{14}+53379
$$

(d) Maximum differences: The maximum difference between two successive primes, together with the last member of the pair separated by that difference, is given in Table 2 .

If we let $p(g)$ be the first prime that follows $g$ composite numbers, then Shanks 
[7] has eonjectured that

$$
\ln p(g) \sim \sqrt{ } g .
$$

The maximum difference observed is 300 , whereas in this region a gap of 1040 may exist.

(e) Largest pair: The largest observed pair is

$$
1000000000149342 \pm 1 .
$$

Acknowledgement. We wish to thank the referee for his suggestions as to the presentation of the above data.

Department of Mathematics

Memorial University of Newfoundland

St. John's, Newfoundland

1. D. H. Lehmer, "Tables concerning the distribution of primes up to 37 millions," 1957 copy deposited in the UMT File \& reviewed in MTAC, v. 13, 1959, pp. 56-57.

2. G. H. HARDY \& J. E. LitTLEWOod, "Some problems of 'partitio numerorum'; III: On the expression of a number as a sum of primes," Acta Math. v. 44, 1923, pp. 1-70.

3. C. L. Baker \& F. J. Gruenberger, The First Six Million Prime Numbers, The Rand Corporation, Santa Monica, published by the Microcard Foundation, Madison, Wisconsin, 1959. Reviewed in Math. Comp., v. 15, 1961, p. 82, RMT4.

4. F. Gruenberger \& G. Armerding, "Statistics on first six million prime numbers," Paper P-2460 of the Rand Corporation, Santa Monica, 1961, 145 pp., $8 \frac{1}{2} \times 11$ in. Copy deposited in UMT File \& reviewed in Math. Comp., v. 19, 1965, pp. 503-505.

5. G. G. AlWAY, "A method of factorisation using a high-speed computer," MTAC, v. 6, no. 37,1952 , pp. $59-60$

6. D. N. Lehmer, List of Prime Numbers from 1 to 10,006,721, Hafner, New York, 1956.

7. D. Shanks, "On maximal gaps between successive primes," Math. Comp., v. 18, 1964, pp. $646-650$. MR $29 * 4745$.

\section{A Note on Expansions Involving Meijer's $G$-Functions}

\section{By Arun Verma}

1. Introduction. The expansions of Meijer's $G$-functions in a series of similar functions and their products with terminating hypergeometric functions, have been studied by several mathematicians as for example Meijer [6], Wimp and Luke [10] and others. It has been shown by the author [7] that these expansions can be written out easily from the known expansions of elementary functions by using induction through Laplace transform and its inverse. However, it is strange to notice that there is not even a single known expansion of Meijer's $G$-function in a series of product of $G$-functions. Also recently, the author [8], [9] has obtained the expansions of $G$-functions of two variables (defined by Agarwal [1]) in a series of similar functions and in a series of products of $G$-functions of two variables and terminating hypergeometric functions. In this paper, using the Laplace transform and its inverse, expansions of Meijer's $G$-function and its extension in a series of products of similar functions are obtained. The results given are

Received June 8, 1966. 